\title{
A INCLUSÃO DA CRIANÇA COM NECESSIDADES ESPECIAIS NA VISÃO DE BERÇARISTAS
}

\author{
FABIANA CRISTINA FRIGIERI DE VITTA \\ Professora assistente do Departamento de Educação Especial da Faculdade de Filoso a e \\ Ciências, da Universidade Estadual Paulista/campus de Marília (SP). \\ fabiana.vitta.to@gmail.com
}

\begin{abstract}
RESUMO
A inserção das crianças de zero a 18 meses em creches poderá estimular o seu desenvolvimento motor e perceptocognitivo, podendo essa fase ser considerada a primeira da educação inclusiva. Objetivou-se verificar as concepções das profissionais do berçário relativas à inserção da criança com necessidades especiais na rotina de atividades desenvolvidas. Foram entrevistadas sete berçaristas da Secretaria Municipal de Educação de Bauru. Os dados, organizados segundo categorias analíticas: conceitos relativos ao processo de inclusão, benefícios para a criança e diferenças entre as crianças nessa faixa etária, foram submetidos à análise qualitativa. Os resultados mostraram que a inclusão de crianças com necessidades especiais é vista com reservas, explicitando ideias preconcebidas sobre a deficiência. Eles se justificam pela falta de conhecimento do desenvolvimento infantil e dos fatores que o envolvem, bem como pelo fato de os profissionais vincularem suas atividades às experiências pessoais.

CRECHES - DESENVOLVIMENTO DA CRIANÇA - EDUCAÇÃO INCLUSIVA
\end{abstract}

\section{ABSTRACT}

THE INCLUSION OF SPECIAL NEEDS CHILDREN IN THE VISION OF DAY CARE CENTER PROFESSIONALS. The inclusion of children from birth to 18 months in day care centers, a phase that can be considered as the first one for inclusive education, may stimulate their motor development and perceptual-cognitive abilities. The goal of this study was to identify how people working in such centers conceive the inclusion of children with special needs in their routine activities. For such, seven women involved in a municipal day care center in the city of Bauru (SP, Brazil) were interviewed. The data - organized according to three analytical categories: believes related to the inclusion process; benefits that it can bring for the child; and differences between children in this age group - were subjected to a qualitative analysis. The results indicated that the inclusion of children with special needs in day-care centers is viewed with reservations. This negative

Este artigo é parte da tese de doutorado (Vitta, 2004), cuja pesquisa foi apoiada pela Coordenação de Aperfeiçoamento de Pessoal de Nível Superior - Capes. 
bias toward disability can be explained by the lack of knowledge related to child development and its main issues as well as by establishing erroneous connections between professional activities and personal experiences.

DAY NURSERIES - CHILD DEVELOPMENT - INCLUSIVE PROCESS

A Educação Infantil passa por um momento de análise de seus componentes ideológicos e organizacionais, devendo-se considerar a educação para a diversidade como um fato a ser incorporado em sua história atual, abrangendo a inclusão' da criança com necessidades especiais.

O Brasil tem uma importante legislação sobre o direito de toda pessoa à educação, conforme pode ser observado no Artigo $4^{\circ}$ da Lei de Diretrizes e Bases da Educação Nacional - LDB. Essa mesma legislação dirige-se de forma particular ao direito à educação das pessoas com necessidades especiais, nos artigos 58, 59 e 60, que tratam da educação especial como modalidade escolar, oferecida preferencialmente na rede regular de ensino, devendo estar presente desde a Educação Infantil (Souza, Silva, 200 I; Brasil, 1999).

Segundo Minto (2002), apesar de a lei assegurar que a oferta de Educação Especial tenha início na faixa etária de zero a 6 anos, vários problemas podem ser reconhecidos. $\bigcirc$ primeiro é referente à utilização da palavra oferta, que não significa assegurar a existência da Educação Especial, e o segundo relaciona-se à imprecisão quanto à faixa etária, ou seja, permite entender que a Educação Especial oferecida pelo Estado pode estar presente em qualquer momento dentro da faixa etária de zero a 6 anos.

Bueno e Ferreira (2003), em trabalho sobre as políticas regionais de Educação Especial, fazem uma análise dos documentos de referência de todos os estados das regiões Sul, Sudeste e Centro-Oeste, três estados do Norte e seis do Nordeste e revelam dados interessantes acerca da organização de serviços de Educação Especial nas diferentes regiões do Brasil. Esses documentos são unânimes em considerar que a oferta deveria ocorrer na Educação básica, incluindo a Educação Infantil, mas somente o Rio de Janeiro estabelecia orientações relativas à organização curricular e pedagógica diferenciada para

I. O termo "inclusão" será utilizado neste trabalho na perspectiva de política de educação. Já o termo "inserção" estará relacionado à introdução de um novo componente a um conjunto e entendido como uma das fases da inclusão. 
os distintos níveis de ensino, destacando a importância da Educação Infantil para o processo de desenvolvimento e a possibilidade de menor rejeição ao processo inclusivo.

Esses dados mostram que a Educação Especial e a inclusiva estão em processo de organização no Brasil, sendo ainda necessária a regulamentação dos serviços oferecidos para a criança menor de 3 anos, esclarecendo como ocorrerá a oferta para aqueles que apresentem deficiências.

Os resultados do censo de 2006 oferecem dados gerais sobre as matrículas nas diferentes modalidades de ensino. Em relação à Educação Especial, restringem-se ao número total de matriculados (375.488), permitindo constatar uma variação negativa de 0,7\% em relação a 2005. Não há informações disponíveis sobre a inserção das crianças com necessidades especiais nas classes comuns das escolas regulares, tampouco é possível distingui-las pelo nível de formação: creche, pré-escola, ensino fundamental etc.

$\mathrm{Na}$ Educação Infantil os dados gerais sobre o número de matrículas: 7.016 .095 indicam uma variação negativa de 2,7\% em relação a 2005, sendo 1.427.942 na creche (aumento de 1\% em relação ao ano anterior)². Não há também no censo escolar descrição sobre a população matriculada e indicações de demanda de crianças com necessidades especiais nessa faixa etária.

Esses dados mostram o quão incompletas são as informações disponíveis sobre Educação Especial na Educação Infantil. Em muitas obras (Prieto, 2002; Mendes, 2002) se observam diferentes indicadores e críticas referentes à organização dos sistemas de Educação Especial e inclusiva, mas pouco é discutido a respeito de sua implementação na faixa etária relativa à creche, principalmente no berçário. A creche, com o tempo, poder-seia transformar no espaço privilegiado para a identificação da criança com atraso e, com base nessa constatação, seria possível encaminhá-la, se necessário, para serviços específicos de diagnóstico e tratamento (Amorim, Yazlle, Rossetti-Ferreira, 2000). Segundo a Secretaria de Educação Especial do Ministério da Educação - Seesp/MEC-, os sistemas educacionais públicos deverão proceder a "identificação das necessidades educacionais especiais e a estimulação do desenvolvimento integral do aluno, bem como

2. http:www.inep.gov.br. 
a intervenção para atenuar possibilidades de atraso no desenvolvimento, decorrentes ou não de fatores genéticos, orgânicos e/ou ambientais" (Brasil, 200I, p.56).

O documento Educação e Cuidado na Primeira Infância - ECPI -, da Organização para a Cooperação e o Desenvolvimento Econômico - OCDE (2002), mostra que a inserção de crianças com necessidades educativas especiais (associadas a deficiências físicas, mentais ou motoras, a dificuldades de assimilação ou a fatores socioeconômicos, linguísticos e culturais), nos programas de primeira infância, é um importante objetivo para todos os países que participaram do estudo. Ressalta que um atendimento eficaz a todas as crianças exige mudanças estruturais nos sistemas de ECPI e um trabalho individualizado, sendo que, com as menores, esse atendimento possibilitará uma intervenção precoce, visando a fortalecer o desenvolvimento global, e preventiva, que incremente as oportunidades educacionais das crianças que correm risco de exclusão social, particularmente aquelas oriundas de famílias pobres ou de origem imigrante.

A inserção da criança deficiente no ambiente escolar regular pode favorecer a experimentação de uma diversidade maior de atividades (Mantoan, 1997; Santos, 1998; Erwin, Schreiber, 1999). Essas promovem o desenvolvimento global da criança, o aprimoramento de habilidades e capacidades, a superação de dificuldades e a descoberta de que ela é parte integrante e atuante de uma sociedade. Sua inserção também possibilita à criança aprender que o ambiente social é constituído de diferentes pessoas, com diferentes características e que essas diferenças devem ser respeitadas, ou seja, que sociedade é sinônimo de diversidade.

Faltam, contudo, estudos sobre a inserção da criança deficiente no berçário. Mendes (2002) destaca que os poucos dados disponíveis se referem a relatos de experiências que não permitem avaliar as atuais condições da educação inclusiva.

Um estudo desenvolvido por Silveira et al. (2003) com o objetivo de levantar o número de crianças com necessidades educacionais especiais inseridas em creches municipais de São Carlos verificou que, dentre essas crianças identificadas, apenas $14,7 \%$ foram definidas como deficientes, sendo que a maioria $(46,1 \%)$ se enquadrou na categoria "crianças de risco", risco este associado tanto a fatores biológicos como ambientais. Credidio (2002), 
ao descrever a experiência de inclusão em creches da prefeitura do Município de São Paulo, relata o fato de algumas crianças matriculadas evidenciarem características de sua deficiência após terem frequentado a creche e de terem formado vínculos, como um dos aspectos que favoreceram o programa de inserção. Ou seja, as crianças ao serem matriculadas quando bebês eram "iguais" aos outros, passando progressivamente a apresentar características próprias de desenvolvimento influenciado por fatores de risco.

Esses dados corroboram a ideia de que todas as crianças inseridas no berçário podem ser consideradas como tendo necessidades particulares. Nessa faixa etária, as diferenças individuais já existem pela própria trajetória do desenvolvimento e as crianças têm diferentes habilidades adquiridas a cada dia. Existem atividades que são próprias de cada fase de desenvolvimento e que permitem aprendizagens apropriadas às suas características e necessidades particulares.

Assim, a Educação Infantil é importante não só para atender a inclusão da criança que já apresenta uma deficiência comprovada, mas também para a prevenção de déficits no desenvolvimento daquelas que se apresentam em ambiente de risco, ou seja, que não têm suas capacidades e habilidades estimuladas no ambiente familiar. Nestes casos, a escola pode complementar essa formação, na medida em que tem a responsabilidade de promover o desenvolvimento integral das crianças.

A Educação Infantil, especialmente o berçário, parece ser o estágio cuja perspectiva inclusiva pode ocorrer de forma mais natural, tanto pelas características particulares inerentes a essa etapa do processo educacional, quanto pelos aspectos desenvolvimentais dessa faixa etária.

Rocha, ao se referir ao trabalho educacional na infância e sua relação com a diversidade na educação infantil, bem fala:

...a incorporação deste mesmo conceito de "infância heterogênea", indicado a partir da sociologia e da antropologia, passa a integrar mais recentemente, no Brasil, as diferentes áreas de conhecimento que se referem à infância, cada qual em seu âmbito, incluindo elementos relativos à diferença e à influência de contextos específicos na construção da diversidade, como afirmação positiva e contrária ao estabelecimento de padrões de normalidade. O horizonte da heterogeneidade de constituição dos sujeitos humanos começa a permear 
todo o discurso referente à infância presente nos diferentes níveis de análise deste objeto e passa a sustentar a definição de uma "Pedagogia da Infância", ao mesmo tempo em que afirma a insuficiência e o limite das orientações pautadas na padronização. (1998/1999, p.5)

A análise de documentos oficiais sobre o assunto, como a Lei de Diretrizes e Bases da Educação Nacional, o Plano Nacional de Educação - PNE - e o Referencial Curricular Nacional para a Educação Infantil - RCNEl -, permitiu verificar que há grande dificuldade na implementação de uma proposta de qualidade para a Educação Infantil que contemple a educação para todos, uma vez que existe um grande espectro de fatores interferindo para que se fundamente uma prática. Às dificuldades do processo de inclusão na creche somam-se outras, relativas a essa fase da Educação Infantil e à instituição propriamente dita, tais como objetivos e conteúdos, financiamento, formação dos profissionais que nela atuam, dentre outros. É, portanto, importante que se conheçam os conceitos das profissionais do berçário sobre a inclusão de crianças com deficiências nas instituições de Educação Infantil.

Assim sendo, este trabalho teve por objetivo verificar as concepções das profissionais do berçário relativas à inserção da criança com necessidades especiais na rotina de atividades por elas desenvolvidas.

\section{PROCEDIMENTOS METODOLÓGICOS}

Este estudo foi realizado com sete funcionárias que atuavam, em 2002, nos berçários de duas escolas de Educação Infantil - creches - integradas à Secretaria Municipal de Educação - SME - de Bauru. A escolha dessas instituições deveu-se ao fato de preencherem as exigências da LDB, ou seja, já faziam parte da Secretaria de Educação. $\bigcirc$ número de participantes da pesquisa foi restrito devido à metodologia escolhida e aos objetivos da pesquisa. Thiollent (2002) a rma que, na prática da pesquisa convencional, a representatividade dos grupos por critérios qualitativos costuma recorrer a "amostras intencionais", isto é, pequeno número de sujeitos escolhidos intencionalmente devido a sua relevância para determinado assunto. Acrescenta que "o princípio de intencionalidade é adequado no contexto da pesquisa social com ênfase nos aspectos qualitativos, onde todas as unidades não são consideradas como equivalentes, ou de relevância igual" (p.62). 
Os dados coletados por meio do protocolo de informações pessoais e profissionais permitiram delinear o perfil das profissionais participantes, conforme o quadro 1 .

\section{QUADRO I}

CARACTERIZAÇÃO DAS PROFISSIONAIS QUANTO A IDADE, ESCOLARIDADE, TEMPO NA EDUCAÇÃO INFANTIL E TEMPO DE BERÇÁRIO

\begin{tabular}{|c|c|c|c|c|c|}
\hline & Pro ssionais & Idade & Escolaridade & Tempo de El & $\begin{array}{l}\text { Tempo no } \\
\text { berçário }\end{array}$ \\
\hline \multirow{4}{*}{$\begin{array}{l}\varangle \\
\pm \\
\frac{U}{U} \\
\mathbb{U} \\
\stackrel{U}{U}\end{array}$} & M & 52 & $2^{\circ}$ grau incompleto & Mais de 5 anos & De 3 a 5 anos \\
\hline & $\begin{array}{l}\text { AM(funcionária } \\
\text { SME) }\end{array}$ & 44 & $\begin{array}{l}2^{\circ} \text { grau completo } \\
\text { (magistério) }\end{array}$ & Mais de 5 anos & Menos de I ano \\
\hline & $\mathrm{R}$ & 45 & $1^{\circ}$ grau completo & Mais de 5 anos & Mais de 5 anos \\
\hline & C & 46 & $1^{\circ}$ grau completo & Mais de 5 anos & Mais de 5 anos \\
\hline \multirow{3}{*}{$\begin{array}{l}\infty \\
\stackrel{U}{U} \\
\frac{U}{U} \\
\dot{U}\end{array}$} & $\mathrm{~T}$ & 50 & $2^{\circ}$ grau completo & De 3 a 5 anos & Menos de I ano \\
\hline & $N$ & 40 & $\begin{array}{l}\text { Superior completo } \\
\text { (em biologia) }\end{array}$ & De I a 2 anos & De I a 2 anos \\
\hline & V & 20 & Finalizando o $2^{\circ} \mathrm{grau}$ & De I a 2 anos & Menos de I ano \\
\hline
\end{tabular}

No berçário da creche A trabalhavam três auxiliares de creche, contratadas pela Secretaria do Bem-Estar Social - Sebes -, sendo que uma pediu para ficar nesse setor e as outras foram designadas, e uma inspetora de alunos contratada pela SME que, por motivos de saúde, foi "reaproveitada" na creche.

No berçário da creche B, eram duas auxiliares de creche da Sebes, ambas indicadas para o berçário pela diretora da creche (quando a SME assumiu), e uma estagiária, também contratada pela Sebes, que trabalhava com um sistema, destinado a estudantes, de estágio remunerado, que não permitia, no entanto, atender às crianças nos momentos de higiene e alimentação. Vale ressaltar que, apesar da regra, a estagiária sempre que necessário auxiliava as profissionais nessas atividades, por uma questão óbvia: falta de mão de obra. O número de profissionais dos berçários dessas instituições, em primeira análise, parece ser condizente com a literatura (Brasil, 1998; Rizzo, 2002), que recomenda um adulto para cada seis ou oito crianças, na faixa etária de 3 a 24 meses (com, 
no mínimo, dois adultos por turma). Uma análise mais minuciosa, no entanto, deve levar em consideração que essas profissionais atendiam, na função de auxiliar de creche, a todas as necessidades do berçário, além de contribuir com possíveis demandas externas. Os serviços gerais, como limpeza, alimentação e cuidados às crianças, eram realizados por todas em esquema de revezamento. A atribuição de cozinheira (lactarista) ficava, na maior parte das vezes, com apenas uma delas.

Após autorização da Secretaria Municipal de Educação de Bauru e das diretoras das duas instituições, os profissionais foram informados sobre o projeto, seus objetivos e procedimentos e convidados a participar da pesquisa. O projeto foi submetido à apreciação do Comitê de Ética da Universidade do Sagrado Coração - CEP/USC -, sendo aprovado em reunião de 30 de outubro de 2002.

A entrevista semiestruturada, por relacionar pontos de interesse, que o entrevistador vai explorando ao longo de seu curso, sem a imposição de uma ordem rígida, foi a técnica escolhida. Segundo Gil (1999), entre todas as técnicas de interrogação, é a que apresenta maior flexibilidade. Ela visa apreender o ponto de vista dos sujeitos. Segundo Minayo (2000), a entrevista, como instrumento de coleta de informações para as ciências sociais, possibilita que a fala revele condições estruturais, sistemas de valores, normas e símbolos, ao mesmo tempo em que transmite as representações de grupos determinados, em condições históricas, socioeconômicas e culturais específicas.

O roteiro foi preparado consoante o objetivo da pesquisa e o referencial bibliográfico da área, versando sobre os temas: possibilidade de inclusão de crianças deficientes no berçário, benefícios para a criança com deficiência quando inserida no berçário e diferenças entre a criança considerada normal e a com deficiência nessa faixa etária.

Para que a coleta de dados ocorresse sem problemas, a entrevistadora foi a própria pesquisadora, que se baseou nos autores Bogdan e Biklen (1994), Gil (1999) e Minayo (2000), quanto aos cuidados a serem tomados nas entrevistas. Estas foram individuais e ocorreram na própria creche, em horário previamente combinado. Foram gravadas e transcritas em arquivos eletrônicos.

O material de cada participante foi ordenado, lido e organizado em quadros compostos por duas colunas, uma destinada à questão feita pelo 
entrevistador e outra à resposta do entrevistado, facilitando a marcação dos temas abordados. Em seguida, os dados foram reorganizados por temas, recortados nos registros das entrevistas, permitindo a releitura do material. A análise nal permitiu confrontar os resultados do material empírico e o teórico, ou seja, com as categorias analíticas estabelecidas como balizas da investigação; buscaram-se as relações dialéticas entre ambas as categorias.

\section{RESULTADOS}

As funcionárias do berçário mostraram insegurança nas respostas quanto à possibilidade de inclusão da criança deficiente no berçário, refletindo principalmente a falta de conhecimento sobre as deficiências. Também observou-se que a experiência prévia de cada entrevistada com indivíduos deficientes influenciou as respostas, nas quais se pôde identificar diversas contradições:

Agora eu nunca tive contato, mas deve ser muito triste você trabalhar com uma criança que é um bebê, mas que fica ali, do jeito que você põe, ali ele não apresenta nada de novo.

A [criança] cega eu já não sei te responder porque eu nunca trabalhei, não tenho experiência neste campo. [...] então a criança de um ano e meio para a criança normal, não faz quase nada, tenta, mas não consegue. Emite grunhidos, não consegue falar. Vai falar bem mais tarde, algumas têm movimentos, algumas não. Algumas conseguem ficar de pé, mas não conseguem se locomover, algumas conseguem, depende do grau de deficiência... Eu comecei a fazer auxiliar de enfermagem para esta área...

O deficiente, ele cabe em qualquer lugar, eu tenho na minha casa como experiência própria, não tinha nada de diferente para ele, e o que foi desenvolvido para ele foi o quê? Foi o coração, foi amor, foi carinho, então ele cabe em qualquer lugar.

Uma das participantes tinha na família um indivíduo adulto com deficiência física e mental, mostrando-se inteiramente a favor da inclusão e colocando o de ciente como igual ao indivíduo normal. No entanto, acabou por apresentar 
uma série de contradições, principalmente ao apontar as dificuldades da inclusão, dizendo, ao mesmo tempo, que elas seriam vencidas com o "coração", o "carinho". Conseguiu descrever dificuldades mais específicas ao falar das deficiências sensoriais, pois com essas não tinha experiência, havendo, segundo a profissional, necessidade de conhecer um método para lidar melhor com essas pessoas:

Eu sou feia, você é bonita, a outra é bonita, a outra é feia, mas é nosso jeito, então eles também são iguaizinhos, eles não têm diferença nenhuma. Agora assim, para trabalhar com um cego e um surdo, também eles não são diferentes, mas só que a gente... com carinho eu sei que a gente vai conseguir, mas a gente teria que ter assim algum, acho, método, alguma coisa para conseguir dialogar, eu tenho certeza que isso vem, vem de dentro de você, espontâneo ele vem, se chegar a vir aqui, vem, porque ele é visto igualzinho, como os outros.

Algumas respostas se mostraram, de início, resistentes à ideia da inclusão, permeadas por exemplos ligados à agressividade do deficiente, à não evolução no desenvolvimento, à necessidade de atenção exclusiva. Em algumas respostas, componentes emocionais tais como sentimentos de compaixão e medo da morte eminente das crianças apareceram. Dificuldades ou preconceitos explícitos (fortemente relacionados à experiência pessoal) puderam ser identificados. Sobre o deficiente mental, estabeleceram relação com comportamentos agressivos e não incluíram na categoria a criança com Síndrome de Down (categoria distinta de deficiência). A dificuldade de entendimento e comunicação apresentada pelo deficiente auditivo e pelo deficiente mental foi o fator mais citado como limitador para o trabalho educativo, sendo que, ao pensar nas crianças de berçário, as profissionais acreditam que deficiências físicas e sensoriais comprometeriam mais o trabalho do que a deficiência mental.

Os conceitos apresentados nas respostas parecem apontar a necessidade de um trabalho mais especí co para facilitar a reflexão sobre inclusão nessa faixa etária. Essa necessidade foi salientada pelas pro ssionais juntamente com a de aumentar o número de pro ssionais e de mudanças físicas e estruturais para que $\mathrm{o}$ atendimento tenha qualidade. 
Se tivesse, como fala?..., não um especialista, uma pessoa acima que podia ajudar, estar ali todo dia [...] uma preparação... se uma funcionária tivesse um preparo maior, um curso maior.

Com o pessoal que está ali dentro, eu acho que não (não é possível a inclusão). Não, porque é como eu disse para você, a gente faz ali o que aprendeu, a gente faz porque fez com os Ihos, a gente não tem preparo nenhum, como na parte da criança perfeita; agora uma criança assim, com qualquer outra de ciência, já era mais complicado e, eu acho que teria que ter um preparo.

Mas a escola tem que ter estrutura para você trabalhar. Porque você põe uma criança que é deficiente, que chuta, que morde, com dois funcionários, para você cuidar não tem como, entendeu? Então a escola tem que ter estrutura. Eu não tenho discriminação, eu acho que ela pode estar, mas desde que tenha estrutura, no sentido de funcionário, de estar atento. [...] E se é deficiente físico, também tem que ter espaço para você andar com a cadeira de rodas. Não tem como, tem que ter os materiais adequados para você estar trabalhando com ele.

Em relação aos benefícios proporcionados pela inclusão à criança com deficiência, novamente apareceram contradições, mas em todas as repostas, com pequenas variações, a criança se beneficiaria, principalmente por ter contato com outras crianças, fato que possibilitaria seu desenvolvimento.

...com esse negócio de inclusão, seria excelente ela vir porque..., mas eu não sei até que ponto, acho que precisava você, em primeiro lugar, conhecer as circunstâncias que ela vive em casa. Agora, de um modo geral, eu acho que seria bom sim, viu, participar, porque a criança desenvolve mais, lógico, evidente, e eu acho que seria muito bom a criança com problemas participar da creche, mas dentro de um lugar que tivesse pessoal especializado em, não tão assim, não tipo Apae, mas um pessoal que tivesse condição, porque a gente, eu não sei como a gente seria, porque aí, sei lá, se teria que ter um cuidado especial, porque se for para tratar como uma criança normal, assim a gente... Agora se tiver algum problema assim, não sei como seria.

...ela ia se desenvolver e ao passo que, e eu acho que, assim, ela tem que conviver com outras crianças normais, porque se ele só ficar no meio de crianças como ela, ela não vai, isso não vai provocar o desenvolvimento dela. 
Eu acho melhor ela vir meio período para o berçário e o resto da tarde ela ficar com o pai e mãe. Ela vai estar com as outras crianças, mesmo no caso da dificuldade dela, ela está no meio das crianças, pode não estar enxergando, mas está brincando, pode não estar escutando, mas pode estar outra criança ali perto, que é aquele convívio social.

No discurso das profissionais, existem diferenças entre as crianças ditas normais e as que são consideradas portadoras de deficiência, sendo que essa se manifesta, principalmente, quando a criança se comunica ou já possui independência suficiente para agredir outras crianças, ou ainda quando "não é capaz" de aprender conceitos formais como cores. Alguns exemplos sobre as dificuldades na inclusão e diferenças entre normais e deficientes referiam-se a indivíduos adultos ou crianças mais velhas, não sendo aplicáveis para a faixa etária em questão. Ou seja, foi possível observar claramente que essas não são características do berçário: no período em que a criança o frequenta, sua comunicação não ocorre por meio de palavras, possui pouca independência para ir e vir ou para agressões físicas ou verbais, e os conceitos formais não são objetivos de aprendizagem, como se constatou na descrição feita pelas profissionais das atividades oferecidas durante a rotina. As próprias profissionais deixavam isso claro quando convidadas a pensar nas diferenças entre as crianças normais e deficientes nessa idade, diziam que não havia muitas. Relataram haver diferenças no repertório de habilidades das crianças que frequentavam o berçário e, nesses casos, apresentavam visões e opiniões diferentes quanto à percepção dos atrasos e formas de promover o desenvolvimento das crianças. No entanto, durante o período de contato com a pesquisadora solicitavam constantemente auxílio para a realização de atividades que possibilitassem o progresso no desenvolvimento das crianças.

\section{DISCUSSÃO}

As concepções que as profissionais têm da deficiência e o atendimento educacional às pessoas com necessidades especiais são importantes fatores que interferem no processo de inclusão.

As profissionais conseguem descrever e lidar com as diferenças existentes entre as crianças do berçário, mas os dados permitiram verificar que existe alguma dificuldade em visualizar o atendimento daquela com necessidades 
especiais, imperando nessa resistência conceitos prévios, nem sempre reais quando se focaliza a criança de zero a 18 meses. Esses conceitos refletem estereótipos, exacerbando as dificuldades individuais verificadas na comparação entre pessoas deficientes e normais, dados esses também encontrados por Beraldo ( I 999), Vitta, Silva e Moraes (2004) e Vitaliano (2003). Ou seja, a declaração explícita da deficiência da criança é um empecilho que surge pelo estigma que lhe é posto.

Mrech ( 1999) mostra que ainda hoje o olhar médico sobre o deficiente sobrepõe o pedagógico, fazendo que a deficiência seja sempre encarada a partir de uma comparação com o modelo de normalidade, assim como com o processo de desenvolvimento da criança normal. Amorim, Yazlle e Rossetti-Ferreira (2000) chamam a atenção para esse rótulo que se baseia nas características orgânicas das deficiências e que acaba por encobrir as habilidades, potencialidades e capacidades dessas crianças e comprometem as ações educacionais que poderiam beneficiá-las.

A percepção de uma criança com atraso no desenvolvimento gera, desde a sua inserção no berçário, desconfortos entre as profissionais quanto à prática das atividades de cuidados e a necessidade de estimulação. Essa criança acaba por tornar-se alvo de preocupações, devido à falta de conhecimentos sobre seu desenvolvimento, aspectos que o influenciam e atividades que o estimulam. Mais preocupante ainda é o fato de essa criança acabar por ficar no berçário mais tempo que as outras por não ter adquirido comportamentos de independência necessários para que seja inserida entre as demais crianças de sua idade, criando uma situação estigmatizante e de difícil solução. Assim, o berçário, que deveria ser por natureza inclusivo, uma vez que a criança apresenta diferenças próprias da idade, se torna, nesse sistema, um fator de exclusão, gerando sérias contradições nos discursos e na prática dirigida à infância.

Essas ideias preconcebidas sobre as dificuldades de lidar com a criança portadora de necessidades especiais refletem uma grande insegurança sobre os procedimentos que devem ser adotados com a criança do berçário. Prova disso está nas dificuldades apontadas para lidar com crianças deficientes: ou as justificativas eram referentes a crianças mais velhas ou adultos, ampliando graus de incapacidade, dificilmente encontrados no bebê que apresenta deficiência, passível de ser inserido no berçário, ou as incapacidades de aprendizagem definidas para essas crianças eram irreais para as atividades desenvolvidas atualmente nos berçários. Resumindo, em relação à criança deficiente, a 
função do berçário difere no discurso e passa do assistencialismo (função definida pelas participantes para as crianças classificadas como normais) para a estimulação do desenvolvimento, o que mostra a dicotomia referente à função do berçário.

A análise dos documentos atuais (PNE e RCNEI) permitiu verificar vários pontos de incongruência a esse respeito, traduzidos principalmente no direito de todas as crianças, desde o nascimento, a cuidados e educação de qualidade. É nessa etapa que se estabelecem as bases do desenvolvimento integral satisfatório e que se poderia contrapor à insuficiente oferta de vagas para atender a demanda social e à falta de prioridade nas metas estabelecidas para a Educação Infantil e a especial. Daí a permanência dos desvios relacionados à função das instituições designadas para atender a esse público. Esses problemas se refletem diretamente na atuação dos profissionais da educação infantil, pois as concepções da instituição, permeadas por suas próprias ideias sobre educação, cuidados, família e sociedade, serão determinantes para o planejamento e execução de sua atividade com a criança.

A mudança na forma de conceber a deficiência requer debates voltados às concepções dos que estão na prática, para que se desmistifiquem conceitos relativos às necessidades especiais das crianças por eles atendidas.

Faltam estudos sobre a inserção da criança deficiente no berçário e o mesmo ocorre em relação aos outros níveis de ensino, sendo que os poucos dados disponíveis referem-se a relatos de experiências que não permitem avaliar as atuais condições da educação inclusiva brasileira (Mendes, 2002).

Masini (1999), ao analisar as expectativas com relação à inclusão escolar do ponto de vista do educador, expõe a inclusão responsável, na qual devem ser discutidas e analisadas as formas possíveis para que isso ocorra em benefício da criança deficiente, mediante projetos educacionais que considerem a dialética teoria-prática. Para isso, é necessário que cada um reflita, com base no conhecimento de seus limites pessoais e de formação, como pode contribuir para a inclusão e que se verifiquem as reais condições de as escolas receberem essa clientela.

Como destaca Bueno (1999), a inclusão da criança com necessidades especiais na escola regular deve acontecer a partir de uma profunda mudança no sistema educacional como um todo, já que sua ineficiência incide tanto sobre o ensino regular como sobre o especial. 
Esse entendimento vai ao encontro da proposta de educação para todos, que amplia a visão sobre o conceito de necessidades educacionais especiais e passa a contemplar o conjunto de indivíduos que se encontram à margem das oportunidades oferecidas pelo atual contexto socioeducacional, contemplando também crianças que vivem na rua, hospitalizadas, que vivem em condições de extrema pobreza, de famílias nômades, minorias linguísticas, étnicas ou culturais ,dentre outras (Bueno, 1999; Amaral, 2003). Oliveira ressalta que,

...do ponto de vista do sistema educacional, lutar contra a exclusão social é ajudar a criança a ampliar, desde cedo, sua relação com o saber, a dominar diferentes linguagens, valores culturais, padrões estéticos e éticos e formas de trabalho baseadas em preceitos científicos, além de propiciar-Ihe o conhecimento de algumas das tecnologias presentes em sua cultura. Nesse processo, cada criança se constitui como sujeito único. (2002, p. 43)

Desse modo, a criança com necessidades especiais pode participar das atividades do berçário, uma vez que suas necessidades são iguais às das outras crianças: atenção e atividades que possibilitem o desenvolvimento de capacidades e habilidades de acordo com o ritmo próprio.

El-Khatib (2002), ao referir-se à inclusão da criança de zero a 3 anos, destaca que suas necessidades não são diferentes das outras crianças. No entanto, quando as atividades são feitas sem uma proposição de objetivos, sem conhecimento de suas partes constituintes e sua implicação para o desenvolvimento motor, perceptocognitivo e socioemocional, é garantido o mínimo para o desenvolvimento de qualquer criança. Esse mínimo não é suficiente para as crianças com necessidades especiais, mas também não o é para as outras crianças de zero a 18 meses. Os aspectos para os quais se deve atentar, nas atividades definidas como cuidados na rotina do berçário, causarão prejuízos e/ou benefícios a qualquer criança ali inserida, na medida em que todas estão em processo de acelerado desenvolvimento.

Repensar as atividades de rotina, que devem ser programadas para ser também educativas e as variações que podem ser introduzidas nesses momentos, deve ser prática considerada para a inserção da criança com necessidades especiais, assim como para o desenvolvimento das que já são atendidas, 
considerando inclusive as indicações contidas no segundo volume do RCNEI, que trata das atividades de cuidados essenciais, priorizando o atendimento individual, de acordo com as características de cada criança.

Devem ser observados outros fatores que interferem na qualidade do trabalho educacional oferecido à criança no berçário, entre eles as expectativas e diretrizes fixadas pelos governantes que influenciam a disposição de recursos materiais, físicos e humanos. A forma de pensar a criança nessa faixa etária, suas necessidades e as obrigações da família e da sociedade em relação ao seu desenvolvimento pleno norteiam a definição do papel das instituições e a oferta de vagas, que podem ou não contemplar todas as crianças. Os sujeitos participantes desta pesquisa referiram-se a esses aspectos e os reafirmaram como obstáculos no processo de inclusão. Vitta, Silva e Moraes (2004) e Vitaliano (2003) reiteram em seus estudos esses achados e destacam a falta de apoio pedagógico e de formação específica.

Os resultados desta pesquisa possibilitaram verificar as concepções das profissionais do berçário relativas à inserção da criança com necessidades especiais na rotina de atividades por elas desenvolvidas. No contexto atual, em que a rotina se restringe a cuidados de alimentação, higiene e repouso, a inserção de crianças com necessidades especiais não é tratada de forma igualitária, seja pelos documentos, seja pelas instituições investigadas. As profissionais resgatam conhecimentos provenientes da experiência prévia com deficientes e reiteram conceitos formulados de uma comparação entre crianças e o que é esperado normalmente para o seu desenvolvimento. Estabelece-se uma ideia equivocada sobre a criança com necessidades especiais, a qual dificulta a proposição de um trabalho que respeite a diversidade característica dessa fase e estimule as capacidades e habilidades de todas as crianças.

A formação do profissional para atuar com a diversidade de crianças inseridas no sistema educacional, é, portanto, uma questão prioritária. Deve conjugar as ideias de cuidado e educação em um atendimento que respeite a individualidade de cada criança, seu ritmo de desenvolvimento, suas características biológicas e socioculturais, mediante a proposição de atividades que sejam significativas no sentido de atender às necessidades pertinentes à idade, mas que também estimulem sua evolução como sujeito que influencia e é influenciado pelo meio em que se insere. 


\section{REFERÊNCIAS BIBLIOGRÁFICAS}

AMARAL, D. P. Paradigmas da inclusão: uma introdução. In: SOBRINHO, F. P. N. (Org.). Inclusão educacional: pesquisa e interfaces. Rio de Janeiro: Livre Expressão, 2003. p. I I-20. AMORIM, K. S.; YAZLLE, C.; ROSSETTI-FERREIRA, M. C. Binômios saúde-doença e cuidado-educação em ambientes coletivos de educação da criança pequena. Revista Brasileira de Crescimento e Desenvolvimento Humano, São Paulo, v. I0, n.2, p.3-18, 2000.

BERALDO, P. B. As percepções dos professores de escola pública sobre a inserção do aluno tido como deficiente mental em classes regulares de ensino. 1999. I 45 f. Tese (Mestrado em Educação Especial) - Universidade Federal de São Carlos, São Carlos.

BOGDAN, R. C.; BIKLEN, S. K. Investigação qualitativa em educação. Porto: Porto Editora, 1994.

BRASIL. Ministério da Educação e do Desporto. Secretaria de Educação Especial. O Que é educação especial. Brasília, 1999. Disponível em: http://www.mec.gov.br/seesp/oquee.shtm. Acesso em: I 4 maio 2000.

Subsídios para credenciamento e funcionamento de instituições de educação infantil, I. Brasília, 1998.

BRASIL. Ministério da Educação. Secretaria de Educação Especial. Diretrizes nacionais para a educação especial na educação básica. Braślia, 2001.

BUENO, J. G. S. Crianças com necessidades educativas especiais, política educacional e a formação de professores: generalistas ou especialistas? Revista Brasileira de Educação Especial, Marília, v.3, n.5, p.7-25, set. 1999.

BUENO, J. G. S.; FERREIRA, J. R. (Coord.). Políticas regionais de educação especial no Brasil. Disponível em: http://www.anped.org.br/26/outrostextos/tegtl5.doc. Acesso em: 21 out. 2003.

CREDIDIO, E. B. Y. A Criança com de ciência quebra a barreira do preconceito: a experiência da inclusão em creches da prefeitura do município de São Paulo. In: MACHADO, M. L. A. Encontros e desencontros em educação infantil. São Paulo: Cortez, 2002. p.29I-296.

EL-KHATIB, U. Falando do desenvolvimento de crianças de zero a três anos. In: PALHARES, M. S.; MARINS, S. C. Escola inclusiva. São Carlos: EdUFSCar, 2002. p.26I-272.

ERWIN, E. J.; SCHREIBER, R. Creating supports for young children with disabilities in natural environments. Early Childhood Education Journal, v.26, n.3, p. 167-17I, 1999.

GIL, A. C. Métodos e técnicas de pesquisa social. 5.ed. São Paulo: Atlas, 1999. 
MANTOAN, M. T. E. A integração de pessoas com deficiência: contribuições para uma reflexão sobre o tema. São Paulo: Memnon; Senac, 1997. Inclusão escolar de de cientes mentais: que formação para professores? p. I $19-127$.

MASINI, E. A. F. S. Quais as expectativas com relação à inclusão escolar do ponto de vista do educador? Temas Sobre Desenvolvimento, São Paulo, v.7, n.42, p.52-54, 1999.

MENDES, E. G. Perspectivas para a construção da escola inclusiva no Brasil. In: PALHARES, M. S.; MARINS, S. C. Escola inclusiva. São Carlos: EdUFSCar, 2002. p.61-85.

MINAYO, M. C. S. O Desafio do conhecimento: pesquisa qualitativa em saúde. 7.ed. São Paulo: Hucitec; Rio de Janeiro: Abrasco, 2000.

MINTO, C. A. Educação especial: da LDB aos planos nacionais de educação - MEC e Proposta da Sociedade Brasileira. In: PALHARES, M. S.; MARINS, S. C. Escola inclusiva. São Carlos: EdUFSCar, 2002. p. I I-39.

MRECH, L. M. Os Desa os da educação especial, o Plano Nacional de Educação e a universidade brasileira. Revista Brasileira de Educação Especial, v.3, n.5, p. I27- I46, set. 1999.

OCDE. Educação e cuidado na primeira infância: grandes desa os. Brasília: Unesco, 2002.

OLIVEIRA, Z. M. R. Educação infantil: fundamentos e métodos. São Paulo: Cortez, 2002.

PRIETO, R. G. A Construção de políticas públicas para todos. In: PALHARES, M. S.; MARINS, S. C. Escola inclusiva. São Carlos: EdUFSCar, 2002. p.45-59.

RIZZO, G. Creche: organização, currículo, montagem e funcionamento. 2.ed. Rio de Janeiro: Bertrand Brasil, 2002.

ROCHA, E. A. C. A Educação da criança: antigos dilemas, novas relações. Pátio Revista Pedagógica, n.7, nov. 1998/jan. 1999. Disponível em: http://www.bibvirt.futuro.usp.br/textos/ humanas/educacao/patio/patio9.html. Acesso em: 14 ago. 2002.

SANTOS, M. T. C. T. De que escola estamos falando na perspectiva da inclusão escolar? Temas Sobre Desenvolvimento, São Paulo, v.7, n.40, p.49, 1998.

SILVEIRA, L. C. et al. G. Inclusão em creches da rede municipal de São Carlos. In: MARQUEZINE, M. C. et al. (Org.). Inclusão. Londrina: Eduel, 2003. p. I21-132. (Col. Perspectivas Multipro ssionais em Educação Especial, v. 2).

SOUZA, P. N. P.; SILVA, E. B. Como entender e aplicar a nova LDB: lei n. 9.364/96. São Paulo: Pioneira Thomson Learning, 2001 .

THIOLLENT, M. J. M. Metodologia de pesquisa-ação. I I .ed. São Paulo: Cortez, 2002.

VITALIANO, C. R. Sugestões para escolar regular atender melhor os alunos com necessidades 
especiais integrados. In: MARQUEZINE, M. C. et al. (Org.). Inclusão. Londrina: Eduel, 2003. p.65-77. (Col. Perspectivas Multipro ssionais em Educação Especial, v. 2).

VITTA, F. C. F. Cuidado e educação nas atividades do berçário e suas implicações na atuação profissional para o desenvolvimento e inclusão da criança de 0 a 18 meses. 2004. Tese (Doutorado em Educação Especial) - Programa de Pós-Graduação em Educação Especial da Universidade Federal de São Carlos, São Carlos.

VITTA, F. C. F.; SILVA, K. P. L; MORAES, M. C. A. F. Conceito sobre a educação da criança deciente, de acordo com professores de educação infantil da cidade de Bauru. Revista Brasileira de Educação Especial, Marília, v. 10, n. I, p.43-58, jan./abr.2004.

Recebido em: abril 2008

Aprovado para publicação em: novembro 2009 